\title{
Content of Phycobilin Pigments in Two Strains of Cyanobacteria of the Atacama Desert, Chile
}

\author{
Iris Pereira ${ }^{1 *}$, Iván Razmilic ${ }^{2}$ and Jeffrey Johansen ${ }^{3}$ \\ ${ }^{1}$ Institute of Biological Sciences, Universidad de Talca, Talca, Chile \\ ${ }^{2}$ Department of Chemistry, Institute of Natural Resources, University of Talca, Talca, Chile, Chile \\ ${ }^{3}$ Department Biology, John Caroll University, Cleveland, USA
}

Received: February 24, 2014; Accepted: June 24, 2014; Published: June 27, 2014

*Corresponding author: Iris Pereira, Institute of Biological Sciences, Universidad de Talca, 2 Norte 685, Talca, Chile, E-mail: ipereira@utalca.cl

\begin{abstract}
The aim of this study was to assess qualitative and quantitatively phycobilin pigments of two nitrogen-fixing Cyanobacteria with the purpose to optimize in the future, the culture conditions to high scale. The studied strains were Nostoc commune and Tolypothrix tenuis, which were gotten from cryptogamic crusts of the Atacama Desert, Chile. They were obtained from a total of twelve transects made between La Serena and Iquique, in the north of Chile. Soil samples of each station were activated in $250 \mathrm{ml}$ Erlenmeyer flasks for 30 min. After they were inoculated in Petri plates and then isolated and massed to a low scale. Once the soil samples were activated, they were cultured for 3 weeks or one month in Petri Plates on agar Z8-N medium and later the inoculates were transferred to $250 \mathrm{ml}$ Erlenmeyer flasks in Z8-N liquid medium under room temperature conditions and continuous irradiance. Chemical determination of pigments and their concentrations were made by spectrophotometry. In both strains, C-phycoerythrin was found in bigger proportion than the C-phycocianin. Strain of Tolypothrix presents more quantity of phycobilin pigments: $0.66 \mathrm{mg} / \mathrm{ml} \mathrm{PE}$ and $0.32 \mathrm{mg} / \mathrm{ml} \mathrm{PC}$. On the other hand The Nostoc strain, showed $0.080 \mathrm{mg} / \mathrm{ml} \mathrm{PE}$ and 0.037 $\mathrm{mg} / \mathrm{ml} \mathrm{PC}$. Due to the high commercial value of these pigments in the market, it is suggested to continue with the detection and determination of these pigments in others strains of cyanobacteria to assess the possibility of their mass culture and exploitation.
\end{abstract}

Keywords: Atacama Desert; Cryptogamic crusts; Phycobilin Pigments Content

\section{Introduction}

Cyanobacteria are organisms capable to fix carbon only as higher plants. Also they can fix atmospheric nitrogen, a compound that is transformed in ammonium and in this way it is liberated to the soil, enriching it with this element, which acts as natural biofertilizer. They also have phycobilin pigments as: phycocyanin and phycoerythrin. Cyanobacteria are part of numerous ecosystems both freshwater and marine, but also of desert soil all over the world. On desert ecosystems, these microorganisms are continuously submitted to a strong hydric, thermic and nutritive stress. Their high tolerance to these conditions allows us to support that these organisms could be easy to culture and in this way achieve the commercialization of these molecules.
The phycobilin pigments have been used successfully in the location of tumor cells in the treatment of cancer and it is known that the C-phycocyanin ameliorates experimental autoimmune encephalomyelitis and induces regulatory T-cells [1]. The light produced by this fluorescence is so distinctive and reliable, that phycobilins may be used as chemical "tags". The pigments are chemically bonded to antibodies, which are then put into a solution of cells. Also these molecules are used in biotechnology [2] and in food due to its antioxidant activity. Based on the obtained information, we proposed to assess qualitative and quantitatively the content of these pigments in two nitrogenfixers cyanobacteria strains from Atacama Desert. Therefore, the following objectives were proposed: a) to assess quali- and quantitatively the phycobilin pigments that these strains possess with the purpose to optimize the conditions of their culture in a high scale.

\section{Materials and Methods \\ Collection of the Samples}

Soil samples came from sites established along different altitudinal transects made in the Atacama Desert in July 2009. Nostoc commune Bornet \& Flahault came from the transect ATA 11-6B (north Calama, 20 56'074”S, 68 57'440”0, $2.964 \mathrm{~m}$ ) and Tolypothrix tenuis Kütz. ex Bornet \& Flahault of ATA 2-3 (Vallenar, $29^{\circ} 22^{\prime} 454^{\prime \prime}, 70^{\circ} 58^{\prime} 936^{\prime \prime} 0,446 \mathrm{~m}$ ).

\section{Activation and Incubation of the Soil Samples}

Soil samples were obtained from cryptogamic crusts, pools and waterfalls. Previous to the taxonomical determination of the species, the soil samples of each site of the transects were sieved and then activated in a shaker for 30 min contained 200 $\mathrm{ml}$ of distilled water. Aliquots were plated in Petri plates in agar Z8 and Z8-N media and were grown under controlled conditions: continuous light, room temperature for a period of 3 weeks to a month. After that time, the colonies were replicated in Petri plates with agar Z8 and Z8- N media with the purpose to obtain unialgal inocula that afterwards were cultured in $250 \mathrm{ml}$ Erlenmeyer flasks with liquid Z8-N media. 


\section{Taxonomical Determination}

For the determination of the species, morphological and reproductive characters were used. Measurements were taken using a Nikon optic microscopy Optiphot model equipped with lucida camera and graduated ocular. The obtained information was submitted to keys and compared with descriptions presented in the specialized bibliography such as [3-6].

\section{Treatment of Samples and Extraction of Phycobilin Pigments}

Cyanobacteria samples had fresh weights, between 70-120 mg; $30 \mathrm{mg}$ of sand were added to those samples. After that, they were washed with concentrated HCL, sieved, calcined, dried and macerated in a mortar with fine sand. To homogenize and extract the pigments, $1 \mathrm{ml}$ of buffer phosphate of $\mathrm{pH} 6.8$ was added to the samples. Then, $2 \mathrm{ml}$ of the treated samples were transferred to an Eppendorf tube and the remnant solution was again washed with two aliquots of $0.5 \mathrm{ml}$ of buffer phosphate. Finally, the samples were centrifuged in a micro- centrifuge at $1000 \mathrm{rpm}$ for $20 \mathrm{~min}$.

\section{Determination of the Concentration of Phycobilin Pigments}

The supernatant obtained was measured in a spectrophotometer at the following wavelength: 455, 565, 592, 618, 645 and $730 \mathrm{~nm}$ using a quartz cell. Readings of absorbance were used for the calculation of the phycobilins pigments concentrations (phycocyanin and phycoerythrin) by the equations of [7]. The results were expressed in an average of three replicates Table 1.

\section{Results and Discussion}

Both strains presented phycobilin pigments (C-phycoerythrin and C-phycocyanin). Tolypothrix tenuis was the strain that presented a major concentration of C- phycoerythrin and

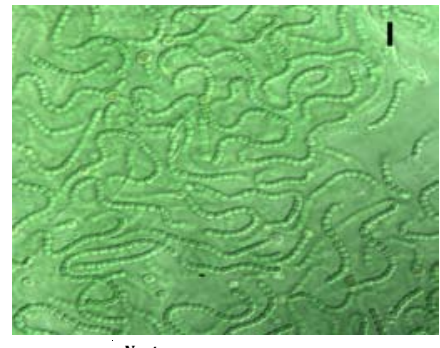

Noctoc commune

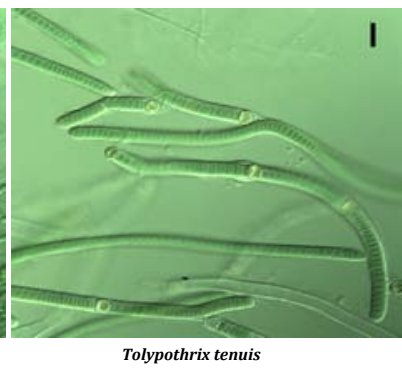

Tolypothrix tenuis
Figure 1: Cyanobacteria strains used in obtaining of phycobilin pigments. The black scale represents $1 \mathrm{~mm}$.

Table 1: Content of phycobilin pigments in the studied strains.

\begin{tabular}{|l|c|c|}
\hline & \multicolumn{2}{|c|}{ Phycobilin pigments } \\
\hline & $\begin{array}{c}\text { C- phycoerythrin } \\
\text { (PE) }\end{array}$ & $\begin{array}{c}\text { C-phycocyanin } \\
\text { (PC) }\end{array}$ \\
\hline Cyanobacteria Strains/ Content & $\mathbf{m g} / \mathbf{m l}$ & $\mathbf{m g} / \mathbf{m l}$ \\
\hline Nostoc commune & $0.080 \pm 0.003$ & $0.037 \pm 0.002$ \\
\hline Tolypothrix tenuis & $0.66 \pm 0.01$ & $0.32 \pm 0.02$ \\
\hline
\end{tabular}

C-phycocyanin.

- In both the studied strains, the C-phycoerythrin was found in major proportion than the C-phycocyanin.

- The Tolypothrix strain had major quantity of phycobilin pigments, with $0.66 \mathrm{mg} / \mathrm{ml} \mathrm{PE}$ and $0.32 \mathrm{mg} / \mathrm{ml}$ of PC. On the other hand, the Nostoc strain had $0.080 \mathrm{mg} / \mathrm{ml} \mathrm{PE}$ and $0.037 \mathrm{mg} / \mathrm{ml} \mathrm{PC}$.

- According to the obtained results, it can be speculated that with a biomass between 100 and $200 \mathrm{mg} / \mathrm{ml}$ of moist weight of algae, $1 \mathrm{mg} / \mathrm{ml}$ of phycoerythrin and $0.5 \mathrm{mg} / \mathrm{ml}$ of phycocyanin can be obtained for the case of Tolypothrix tenuis.

- According to the high value of these pigments in the market (phycocyanin about of US \$535 the milligram and phycoerythrin around of US \$244 the milligram), depending on the type of species (Sigma-Aldrich), it is suggested to continue with the detection and determination of these pigments in other cyanobacteria strains to assess the possibility of their mass culture and exploitation.

- To obtain one milligram of phycoerythrin and phycocyanin from the more rentable strain (Tolypothrix tenuis) the commercial cost was of US $\$ 4$ and US $\$ 7.5$ respectively. This value includes the cost of reagents, isolation, culture and harvest.

\section{Conclusions}

Based on the obtained results, we can conclude that both strains of cyanobacteria from the Atacama Desert possess different proportions of phyocyanin and phycoerythrin. The percentage of yields of these two pigments could be increased under different types of light allowing to increase the added value of these natural resources, due to the "chromatic adaptation" that cyanobacteria possess.

\section{Acknowledgments}

The authors thank to project 2009-2010 Biodiversity of terrestrial cyanobacteria of Atacama Desert, Chile financed by NSF (National Science Foundation) and to the Talca University for the facilities provided in the development of this study.

\section{References}

1. Pentón-Rol G, Martínez-Sánchez G, Cervantes-Llanos $\mathrm{M}$ et al. C-Phycocyanin ameliorates experimental autoimmune encephalomyelitis and induces regulatory T cells. Int. Immunopharmacology. 2011; 11: 2938.

2. Eriksen NT. Production of phycocyanin- a pigment with applications in biology, biotechnology, foods and medicine. Appl Microbiol Biotechnol. 2008; 80: -84 .

3. Desikachary TV. Cyanophyta. New Delhi: Indian Council of Agricultural Research. 1959; 1-686.

4. Geitler L, Cyanophyceae. In: Rabenhorst L ed. Kryptogammenflora von Deutschland, Osterreich, under de Sweitz. Leipzig: Akademische Verlagsgesellschaft. 1932;14: 673-1056. 
5. Komarèk J, Anagnostidis K. Cyanoprokaryota 1. Teil: Chroococcales. In: Ettl H, Gartner G, Heynig H, Mollenhauer D eds. Süsswasserflora von Mitteleuropa 19/1, Gustav Fischer, Jena-Stuttgart-Lübeck-Ulm. 1998; 548.

6. Komarèk J, Anagnostidis K. Cyanoprokaryota 2. Teil/ 2nd Part: Oscillatoriales. In: Budel B, Krienitz L, Gartner G, Schegerl M eds.
Süsswasserflora von Mitteleuropa 19/2, Heidelberg: Elsevier/ Spektrum. 2005; 759 .

7. Kursar TA, Alberte RS. Photosynthetic unit organization in a red alga: Relationships between light-harvesting pigments and reaction centers. Plant Physiology. 1983; 72(2): 409-414. 